\title{
Differentially Expressed Long-Term Salinity Responsive Sequences in Halophyte Suaeda maritima (L.) Dumort
}

\author{
Krishnamurthi Saraswathi Shrikanth, Ajay Kumar Parida, Kozhikottuthodi Puthanveedu Girivasan
}

\section{ABSTRACT}

Salinity is a major abiotic stress that affects plant growth and productivity. To cope with salt stress, plants express large number of salt responsive genes and proteins that are involved in a wide range of cellular functions. In the present study, halophytic plant Suaeda maritima (L.) Dumort. were hydroponically exposed to $\mathrm{NaCl}$ for understanding the molecular mechanisms behind salinity tolerance using PCR-based Suppressive Subtractive Hybridization (SSH). Two cDNA subtraction libraries were constructed between Suaeda maritima $\mathbf{X}$ Sesuvium portulacastrum and Suaeda maritima X Salicornia brachiata to identify differentially expressed genes from leaves exposed to $200 \mathrm{mM} \mathrm{NaCl}$ treatment for 14 days. A total of 224 clones from both libraries were assembled into 109 unique-ESTs grouped into different functional categories. Based on GO functional annotation, the expressed sequences like Oxygen-evolving enhancer protein1, AARF domain-containing kinase protein, V-type proton ATPase subunitd2, RMD5 homologA, and ABC transporter G35 that are involved in photosynthesis, cellular transport, cell rescue and defense, polyubiquitination and secondary metabolism played a significant role implying a complex response to salt in S. maritima. This is the first report that SSH could facilitate screening across species and family specific identification of salt responsive genes provides insight into biological mechanisms underlying salinity response.

Keywords: Abiotic stress, expressed sequence tags, salinity, salt tolerance.

Published Online: February 8, 2022

ISSN: 2684-5199

DOI : $10.24018 /$ ejbio.2022.3.1.322

\section{K. Shrikanth}

Department of Molecular Biology and Biotechnology, M.S. Swaminathan Research Foundation, Chennai and Department of Botany, Government Arts College, Nandanam, Chennai, India.

(e-mail: shrimicro3@gmail.com)

A. K. Parida*

Institute of Life Science,

Bhubaneswar, India.

(e-mail:drajayparida@gmail.com)

K. P. Girivasan*

Department of Botany, Government Arts College, Nandanam, Chennai, India.

(e-mail: girivasankp1970@gmail.com)

*Corresponding Author

\section{INTRODUCTION}

Salinity is one of the most important abiotic stresses that adversely affect plant germination, growth and ultimately yield. Today, worldwide $20 \%$ of total cultivated lands and $33 \%$ of irrigated agricultural lands are afflicted by high salinity (Golldack et al., 2014). The effects of salt on crops, there is a need to increase food production at a rate of $1.8 \%$ per year to feed the increasing world population, which is projected to be 9.5 billion by the year 2050. In this context, developing crop plants that can sustain productivity under salinity stress conditions becomes important (Hossain, 2019; Shahid et al., 2020).

Halophytes, also called as salt loving plant of about 500 species, grow normally in heavily saline soils constituting approximately $0.14 \%$ of known plant species. It exhibits complex salt tolerance mechanism because of their unique specialized structures includes salt glands, bladder hairs, succulent tissues, and thick layers of suberin (Flowers \& Colmer, 2015). The salt-tolerant mechanisms of halophytes can be divided into two main categories: (i) preventing or reducing the amount of salt being uptake by plant tissue and (ii) reducing the concentration of salt present in the cytoplasm. Thus, halophytes are ideal plants for studying the mechanism of salt tolerance as they survive, grow normally for longer time spans and complete their life cycle in saline environments (Yuan et al., 2019; Zhang et al., 2020). Suaeda maritima (L.) Dumort is an herbaceous, facultative, annual halophyte with succulent leaves that grows up to $30 \mathrm{~cm}$ in height that is native to saline soils of arid and semiarid regions. This species is a self-pollinated bisexual dicot of the family Chenopodiaceae (now included in the family Amaranthaceae) with $2 n=36$ chromosomes that produces reddish brown seeds (Sahu \& Shaw, 2009; Alhdad \& Flowers, 2020; Certain et al., 2021). It exhibits high resistance to alkali stresses and grows well with salt content even without salt glands or bladders on its leaves to modulate their tissue ion concentration. It not only performs exclusion of salt but also quite efficiently compartmentalizes the excess salt in to the cell vacuoles similar to Suaeda salsa (Li et al., 2020). Therefore, in the present study, S. maritima has been selected as a model for the study of physiological and molecular characterization of salt tolerance in plants.

Suppression subtractive hybridization ( $\mathrm{SSH}$ ) is a simple and versatile technique for selectively amplifying cDNA fragments of differentially expressed genes or an effective tool for functional genomics study. It enables researchers to compare two populations of mRNAs and obtain clones of 
genes that were expressed in one population but not in the other. This method can develop libraries that include both scarce and abundant genes, potentially yielding a more diverse gene pool than other techniques to identify specific genes (i.e. stress responsive genes). By using two specific hybridizations and two PCR specific amplifications, $\mathrm{SSH}$ has the advantage of decreasing false positive rate, improve the screening efficiency, higher degree of target sequence enrichment and higher consistency (Diatchenko et al., 1996). It has been successfully applied in the identification of salt responsive genes in various plants such as Thellungiella halophila (Wang et al., 2004), Aeluropus littoralis (Zouari et al., 2007), Bruguiera cylindrica (Wong et al., 2007), Chenopodium album (Gu at al., 2011), Mesembryanthemum crystallinum (Roeurn et al., 2016) and Suaeda nudiflora (Jothiramshekar et al., 2020).

In the present study, two SSH cDNA libraries were targeted salt responsive transcripts of Suaeda maritima (L.) Dumort., as experimental tool of Suaeda maritima $X$ Sesuvium portulacastrum and Suaeda maritima $X$ Salicornia brachiata (hereafter refereed as $S M X S P$ and $S M X S B$ library) that will result in family specific and genus specific ESTs without being stressed to the plants [as all of them are halophytes]. The optimal salt concentration for its growth is $200 \mathrm{mM} \mathrm{NaCl}$, but it grows well at a range of $100 \mathrm{mM}$ to $400 \mathrm{mM} \mathrm{NaCl}$ were observed in our earlier experiments (Shrikanth et al., 2017). This study provides new insights into complex biological phenomena and thereby allows a better understanding of salt response pathways in non-model plant species.

\section{MATERIALS AND METHODS}

\section{A. Plant Material and Salt Treatment}

Seedlings of Suaeda maritima (L.) Dumort., and Salicornia brachiata Roxb., were collected from the Pichavaram mangrove wetlands, Chidambaram district in Tamilnadu. Sesuvium portulacastrum (L.) L., stem cuttings were obtained from Pichavaram mangrove area and maintained under field conditions inside the MSSRF campus, Chennai. Seeds were sown in sterile vermiculite and allowed to germinate under greenhouse conditions $\left(32 \pm 3^{\circ} \mathrm{C}\right.$ daytime and $29 \pm 2^{\circ} \mathrm{C}$ nighttime temperatures; $80-90 \%$ RH). Pots were sprinkled with tap water every morning. Seedlings were later carefully removed from the vermiculite pots using water without disturbing the root system and hydroponically acclimatized in a growth chamber maintained at $24 \pm 3^{\circ} \mathrm{C}, 70-75 \%$ relative humidity with $14 \mathrm{~h}$ light $(200 \mu \mathrm{mol} \mathrm{m}-2 \mathrm{~s}-1) / 10 \mathrm{~h}$ dark cycle. The hydroponic medium constituted Modified Hoagland's Solution during acclimatization for 7 days and in the same medium with $200 \mathrm{mM} \mathrm{NaCl}$ salt treatment for 14 days.

\section{B. Total RNA Extraction and mRNA Purification}

TRI reagent-based extraction procedure (Sigma aldrich) were used for S. maritima and S. brachiata. A modified CTAB extraction procedure that included extraction with guanidium hydrochloride were employed for total extraction from $S$. portulacastrum. mRNA purifications were performed using Machery and Nagel mini-prep kit following the manufacturer's instructions with minor changes. Quantity of mRNA was verified using $1.2 \%$ agarose gel electrophoresis by comparing with known concentration of mammalian mRNA supplied with Clonetech's cDNA library kit.

\section{C. cDNA Synthesis and Suppression Subtractive Hybridization (SSH)}

Based on the quantity of RNA obtained, a cDNA synthesis step using SMARTer cDNA synthesis kit (Clontech) to generate cDNAs from limited amounts of total RNA or mRNA. SSH kit (Clontech) was used to prepare the cDNA libraries using cDNAs containing rsa I restriction site at their ends. Two cDNA subtraction libraries between Suaeda maritima (SM) X Sesuvium portulacastrum (SP) and Suaeda maritima (SM) X Salicornia brachiata $(S B)$ were constructed from $200 \mathrm{mM} \mathrm{NaCl}$ treated plants for 14 days. All the procedures were according to the manufacturer's instructions with slight modifications. Subtracted cDNAs were cloned in T-vector (MBI Fermentas) and transformed into E. coli Omnimax RT1 (Invitrogen) chemically competent cells. Recombination efficiency of the clones were analyzed using colony PCR with the help of M13 forward and reverse universal primers.

\section{Differential Screening of the Subtracted Clones}

Fifty nanogram of plasmid DNA from each subtracted clone and the appropriate probes for blots were generated through PCR amplification of the cDNA inserts (for which sequence information is already available) using M13 forward and reverse universal primers. The probes were gel eluted using Eppendorfs Perfectprep ${ }^{\circledR}$ Gel Cleanup kit, following the manufacturer's protocol. The denatured probe DNA was added to the tube of Amersham Rediprime random primer labelling kit and the mixed contents was purified using Pharmacia ProbeQuant G-50 column. Hybridization using the 32P labelled probe DNA was done in DIG hybridization buffer and incubated overnight. The membrane was washed using SSC and the washed membranes were saran wrapped and exposed to an X-ray film in a cassette for 3-4 days at $80^{\circ} \mathrm{C}$. The X-ray film was processed in the developer solution then rinsed in water and fixed.

\section{E. Sequencing and Bioinformatics Analysis}

Randomly selected plasmid clones from subtracted library were sequenced using M13 forward and reverse sequencing primers. Sequencing reactions were performed using Applied Biosystems automated sequencing kit according to the manufacturer's instructions. Sequences longer than $100 \mathrm{bp}$ were treated for vector trimming and deletion of adaptors, poly $\mathrm{A} / \mathrm{T}$ ends and low-quality regions using VecScreen software. The cleaned sequences were collected and assembled by CAP3, using default parameters to generate contigs and singletons (Huang \& Madan, 1999). After analysis, unique-ESTs sequences were submitted to dBEST database of NCBI. The obtained sequence information was queried against the non-redundant (nr) peptide sequences in NCBI database (http://www.ncbi.nlm.nih.gov/BLAST) with blastn and tblastx (Altschul et al., 1990). Functional annotation and analysis was performed by using Blast2GO tool (www.blast2go.com), web-based freeware following the standard procedure of BLASTX for unigenes dataset (parameters: nr database, high scoring segment pair (HSP) cutoff length 33, report 20 blast hits, maximum E-value 1.0E3 ), followed by mapping and annotation (parameters: E-value 
hit filter 1.0E-6, annotation cutoff 55, GO weight 5, HSP-hit coverage cutoff 20). GO terms were summarized according to their molecular functions, biological processes, and cellular components. Enzyme mapping of annotated sequences was performed by using direct GO to Enzyme mapping and used to query the Kyoto Encyclopaedia of Genes and Genomes (KEGG) to define the KEGG orthologs (KOs) and metabolic pathways.

\section{RESUlTS AND DiscUSSION}

\section{A. Effect of Salt Treatment on S. maritima}

The plants grew well in vermiculite containing medium. However, when they were transferred to a hydroponic medium, some of the plants wilted. It is possible that during transfer from solid vermiculite medium roots were damaged and those plants with damaged roots were not able to survive. Plants that survived and were transferred to different $\mathrm{NaCl}$ concentrations resulted in various morphological changes in the leaves overtime. The plants displayed a linear decrease in leaf number and size under salt concentrations of 300 to $500 \mathrm{mM}$. At $500 \mathrm{mM} \mathrm{NaCl}$, the plants showed signs of severe stress at later stages of treatment. At 100 and $200 \mathrm{mM} \mathrm{NaCl}$, the plants did not show signs of salt injury, were able to produce new leaves, and continued to grow comparatively similar or better than the control plants (Fig.1). Thus, our results show that all the species can withstand lower salt concentrations, higher concentrations above $200 \mathrm{mM}$ affect its growth over long periods.

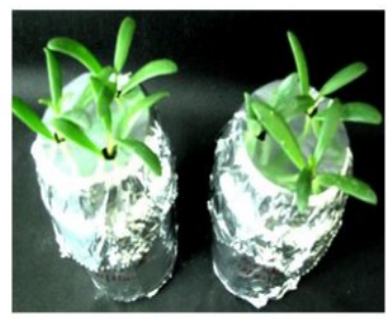

A

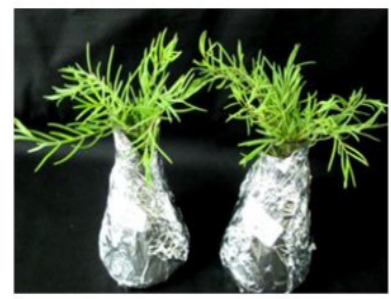

C

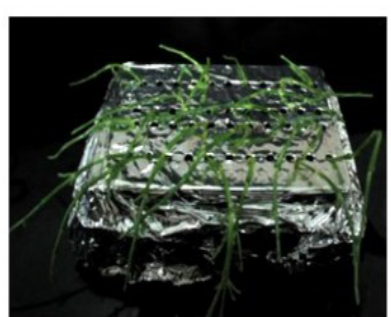

E

Fig. 1. Effect of long-term salt treatment on halophytes. A, B $-S$. portulacastrum cuttings in acclimatization medium (MHS) and MHS+200mM NaCl containing medium respectively; C, D - S. maritima seedlings in acclimatization medium (MHS) and MHS $+200 \mathrm{mM} \mathrm{NaCl}$ containing medium respectively; E, F - S. brachiata seedlings in acclimatization medium (MHS) and MHS $+200 \mathrm{mM} \mathrm{NaCl}$ containing medium respectively.

\section{B. SSH Library of S.maritima under $200 \mathrm{mM}$ Salt}

RNA extraction from $\mathrm{NaCl}$ treated plants resulted in good concentrations of RNA. SMARTer cDNA synthesis kit were used to synthesis cDNA and were purified using Chroma-spin column which were used for rsa I digestion. The SSH library were constructed using cDNA from leaves exposed to $200 \mathrm{mM} \mathrm{NaCl}$ S.maritima as tester and that $200 \mathrm{mM} \mathrm{NaCl}$ of S.portulacastrum and S.brachiata as driver. Subtraction procedures were verified for efficiency according to the manufacturer's recommendations at each step (Fig. 2). Efficiency of adaptor ligation is crucial for good cDNA subtraction were verified using actin specific primers.

Subtracted cDNA fragments were cloned, and randomly selected for sequencing 224 clones (162 in SMXSP + 62 in SMXSB) from both the libraries and checked by colony PCR amplification using M13 universal primer to detect the presence of cDNA inserts and to estimate the size. This resulted in the identification of 109 ESTs were putatively identified and found to contain inserts ranging from 50 to 900 bp were submitted to NCBI. Differential screening was performed for the two libraries using subtracted cDNA probes across species and families clearly resulted in common and specific clones in individual libraries (Fig.3).

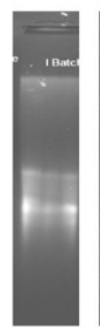

A

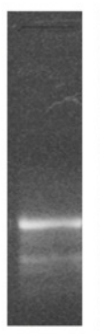

B

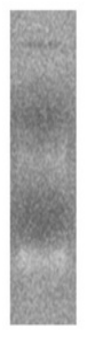

C
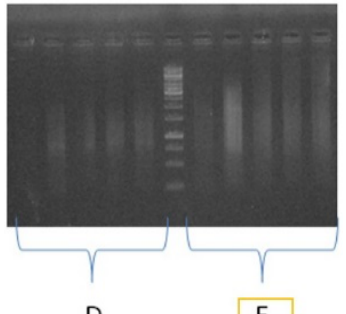

E

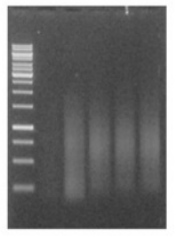

F

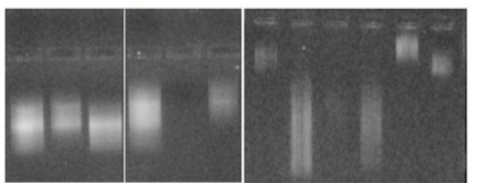

G

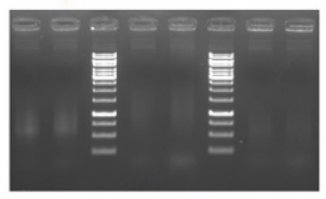

J

$\mathrm{L}$

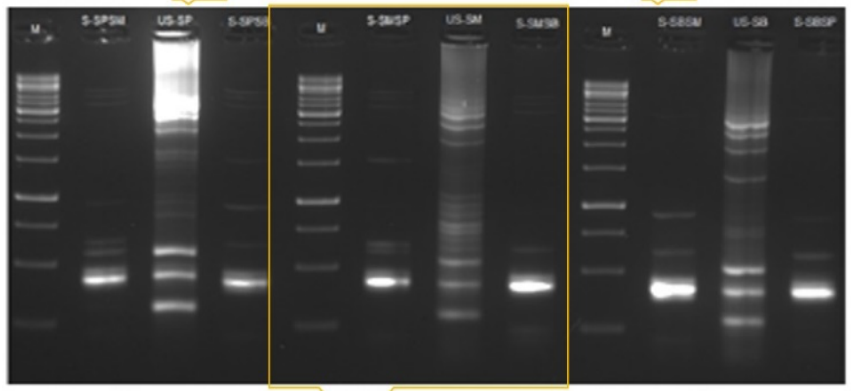

M

O
Fig. 2. Evaluation of subtraction efficiency by PCR. A, B, C - Leaf total RNA extracted from $S$. portulacastrum (SP), S. maritima (SM) and $S$. brachiata $(\mathrm{SB})$ respectively; D, E, F - cDNA synthesized from SP, using SM (mRNA template) and SB respectively using SMARTer cDNA synthesis kit; G, H, I - Purified cDNAs from SP, SM and SB respectively; J, K, L - Rsa I digested cDNAs from SP, SM and SB respectively; $\mathrm{M}, \mathrm{N}, \mathrm{O}-$ Unsubtracted and subtracted cDNA from SP, SM and SB respectively after secondary nested PCR. 


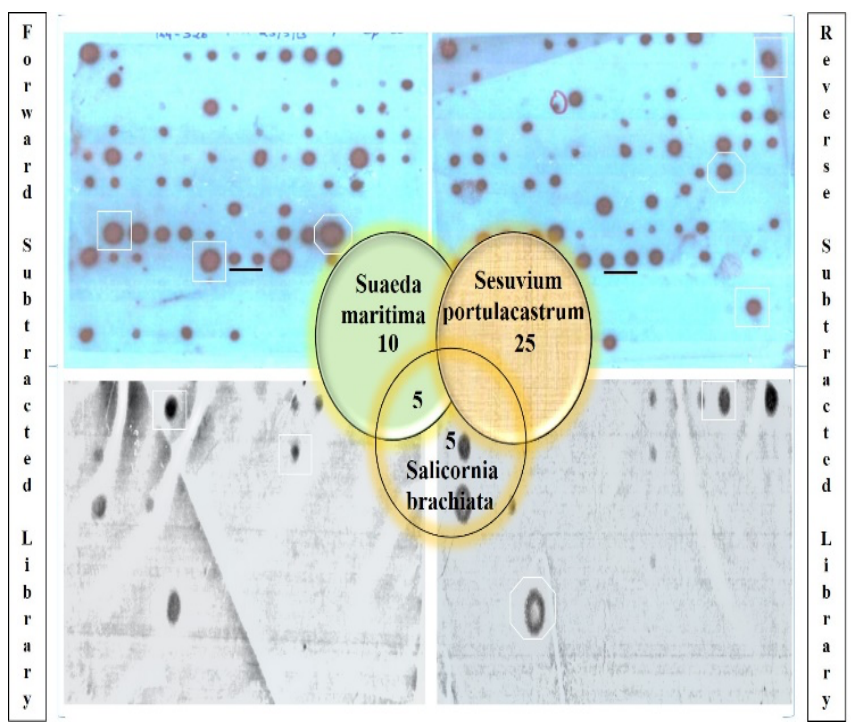

Fig. 3. Dot-blot differential expression screening from subtracted libraries of $S$. maritima. Forward - Specific to $S M$ leaf induced during $\mathrm{NaCl}$ treatment; Reverse - Specific to $S P$ and $S B$ leaf induced during $\mathrm{NaCl}$ treatment.

\section{Putative Identification of Salt Responsive ESTs in Sueada maritima}

Out of 224 sequences 109 ESTs showed similarity with known or unknown category of genes in NCBI databse. The genes identified in the study includes RMD5 homolog A, Stress up regulated Nod 19 protein, $A B C$ transporter $G$ family member 35, Oxygen-evolving enhancer protein 1, CAAX amino terminal protease, aarF domain-containing protein kinase, Thylakoid Assembly 8, Probable glutathione Stransferase, Trifunctional UDP-glucose 4,6 dehydratase/UDP-4-keto-6-deoxy-D-glucose3,5epimerase /UDP-4-keto-L-rhamnose reductase RHM1 belongs to SMXSP library (Table I) whereas CBS domain-containing protein CBSX3, V-type proton ATPase subunit d2, Magnesium-chelatase subunit $\mathrm{ChlH}$, Probable choline kinase 1 belongs to SMXSB library (Table II).

TABLE I: DIFFERENTIALLY EXPRESSED SALT RESPONSIVE SM X SP LIBRARY ESTS THAT WERE ISOLATED BY SUPPRESSION SUBTRACTIVE HYBRIDIZATION (SSH)

\begin{tabular}{|c|c|c|c|c|c|c|}
\hline $\begin{array}{l}\text { GenBank } \\
\text { Accession }\end{array}$ & Putative Annotated Protein & $\begin{array}{l}\text { ESTs } \\
\text { Clones }\end{array}$ & $\begin{array}{l}\text { Length } \\
\text { (bp) }\end{array}$ & Homology Speices & $\begin{array}{l}\text { Identity } \\
(\%)\end{array}$ & E-Value \\
\hline JZ905155 & RMD5 homolog A & 2 & 256 & \multirow{2}{*}{$\begin{array}{l}\text { Chenopodium quinoa } \\
\text { Beta vulgaris subsp. } \\
\text { vulgaris }\end{array}$} & 98 & $3.75 \mathrm{E}-10$ \\
\hline JZ905160 & Stress up-regulated Nod 19 protein & 1 & 912 & & 90 & $3.18 \mathrm{E}-32$ \\
\hline JZ905161 & $\mathrm{ABC}$ transporter $\mathrm{G}$ family member 35 & 2 & 87 & $\begin{array}{l}\text { Beta vulgaris subsp. } \\
\text { vulgaris }\end{array}$ & 93 & $2.16 \mathrm{E}-9$ \\
\hline JZ905163 & Oxygen-evolving enhancer protein 1 & 2 & 281 & Salicornia europaea & 94 & $1.67 \mathrm{E}-55$ \\
\hline JZ905174 & CAAX amino terminal protease & 1 & 518 & $\begin{array}{l}\text { Beta vulgaris subsp. } \\
\text { vulgaris }\end{array}$ & 94 & $\begin{array}{l}7.87 \mathrm{E}- \\
108\end{array}$ \\
\hline JZ905176 & Thylakoid assembly 8 & 1 & 335 & Spinacia oleracea & 73 & $3.84 \mathrm{E}-22$ \\
\hline JZ905184 & $\begin{array}{l}\text { aarF domain-containing protein kinase } \\
\text { At1g79600 }\end{array}$ & 5 & 583 & $\begin{array}{l}\text { Beta vulgaris subsp. } \\
\text { vulgaris }\end{array}$ & 80 & $1.34 \mathrm{E}-55$ \\
\hline JZ905203 & Probable glutathione S-transferase & 1 & 140 & $\begin{array}{l}\text { Beta vulgaris subsp. } \\
\text { vulgaris }\end{array}$ & 89 & $4.52 \mathrm{E}-12$ \\
\hline JZ905217 & Trifunctional UDP RHM1 & 1 & 286 & Chenopodium quinoa & 93 & $3.50 \mathrm{E}-53$ \\
\hline
\end{tabular}

TABLE II: DIFFERENTIALLY EXPRESSED SALT RESPONSIVE SM X SB LIBRARY ESTS THAT WERE ISOLATED BY SUPPRESSION SUBTRACTIVE HYBRIDIZATION (SSH)

\begin{tabular}{|c|c|c|c|c|c|c|}
\hline $\begin{array}{l}\text { GenBank } \\
\text { Accession }\end{array}$ & Putative Annotated Protein & $\begin{array}{c}\text { ESTs } \\
\text { Clones } \\
\end{array}$ & $\begin{array}{c}\text { Length } \\
\text { (bp) }\end{array}$ & Homology Speices & $\begin{array}{c}\text { Identity } \\
(\%) \\
\end{array}$ & E-Value \\
\hline JZ905223 & CBS domain-containing protein CBSX3 & 1 & 439 & Cucurbita moschata & 96 & $8.22 \mathrm{E}-80$ \\
\hline JZ905228 & V-type proton ATPase subunit d2 & 4 & 372 & Camellia sinensis & 99 & $2.70 \mathrm{E}-40$ \\
\hline JZ905236 & Magnesium-chelatase subunit $\mathrm{ChlH}$, & 1 & 257 & Papaver somniferum & 96 & $8.68 \mathrm{E}-50$ \\
\hline JZ905248 & Probable choline kinase 1 & 1 & 356 & $\begin{array}{c}\text { Beta vulgaris subsp. } \\
\text { vulgaris }\end{array}$ & 88 & $2.83 \mathrm{E}-31$ \\
\hline
\end{tabular}

\section{Possible Roles of Identified ESTs in S. maritima} Salinity Response with Respect to Their Functional Classification

The identified unique-ESTs were classified into nine functional groups based on Gene Ontology annotation of cellular component, molecular function and biological processes includes energy metabolism (2), photosynthesis (1), protein metabolism (2), stress and defense response (3), membrane transporters (1), structural genes (2), gene expression and RNA metabolism (1), secondary metabolism (2) and unknown Fig. 4. Biological processes, location, role and their specific function of the identified salt responsive ESTs as shown in Fig. 5 and Table III.

\section{E. Photosynthesis and Energy metabolism}

Oxygen evolving enhancer protein 1 (OEE1) and Magnesium chelatase $\mathrm{ChlH}$ were under the category of photosynthesis and energy metabolism. Oxygen evolving enhancer protein 1 (OEE1) is a major nuclear-encoded chloroplast protein subunit of 33 Kilo Daltons $(\mathrm{kDa})$. It plays a crucial component of photosystem II (PSII) which provides the binding site for other subunits peripherally located on the luminal side of the thylakoid membrane. Previous studies shown in various halophytes like Bruguiera gymnorrhiza, Suaeda aegyptiaca and S. maritima, enhanced levels of OEE1 under salinity leads to the restoration of oxygen evolution, stabilize the ligation of Mn cluster and promoting rapid redox cycling in plants (Koichi et al., 2000; Askari et al., 2006; Alhdad et al., 2013). A similar result was obtained in our 
study (clone no.MP 34) implies that OEE1 is the essential protein for oxygen evolution and PSII stability under $\mathrm{NaCl}$ treatment (Fig. 5). Another photosynthetic protein was upregulated in the present study is Magnesium chelatase ChlH (clone no. MB 23), an ATP-dependent subunit of three component enzyme that catalyzes the insertion of magnesium ion into protoporphyrin IX to yield Mg-protoporphyrin IX during synthesis of chlorophyll (Table III). In Arabidopsis thaliana and salt-treated halophyte Tangut nitraria, it involves in the binding of $\mathrm{Ch} 1 \mathrm{H}$ subunit and porphyrins on chloroplast membranes, thereby photosensitizing the chlorophyll intermediates that leads to contribute photo oxidative stress tolerance in plants (Begcy et al., 2011; Cheng et al., 2015).

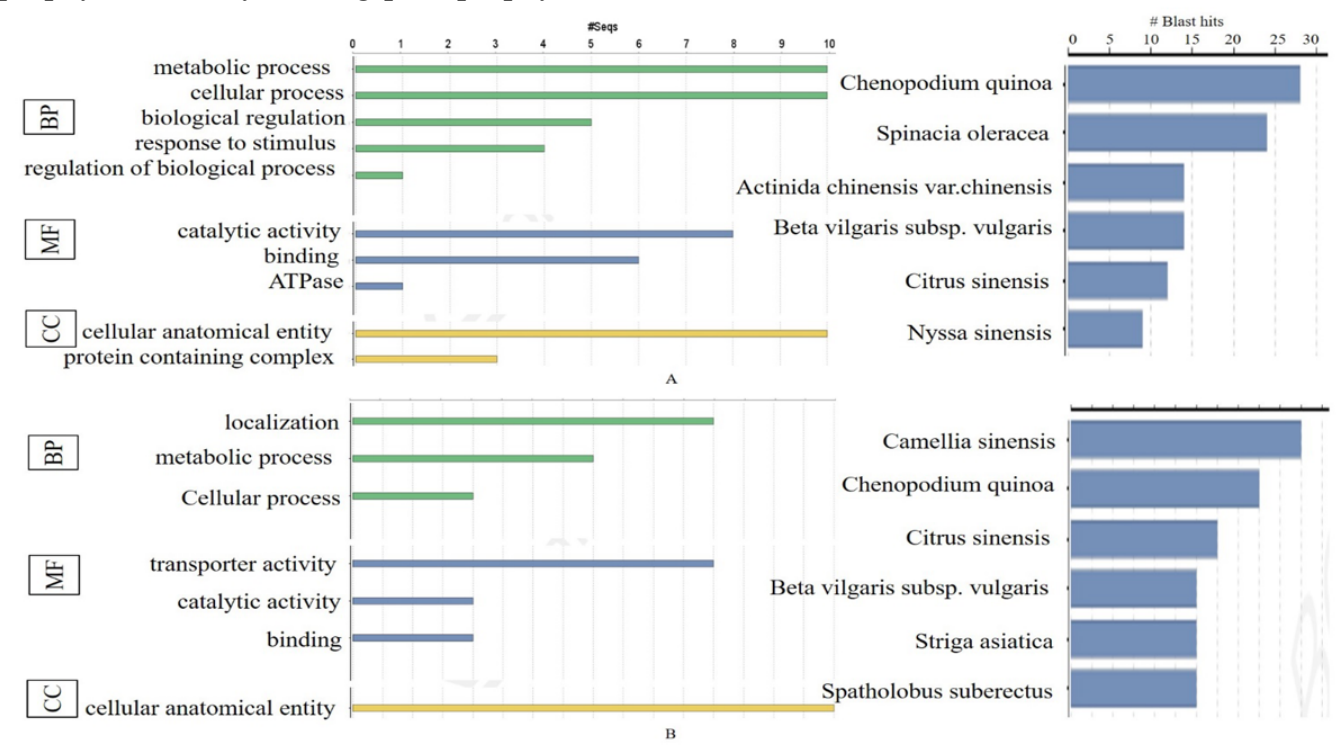

Fig. 4. Top hits Blast species with Go classification of unisequences in the SSH cDNA library. Functional assignment of the unisequences were performed with significant hits in the database. The bar graph shows the distribution of unisequences in three principal GO categories: biological process, cellular component and molecular function A-SMXSP lbrary; B -SMXSB library.
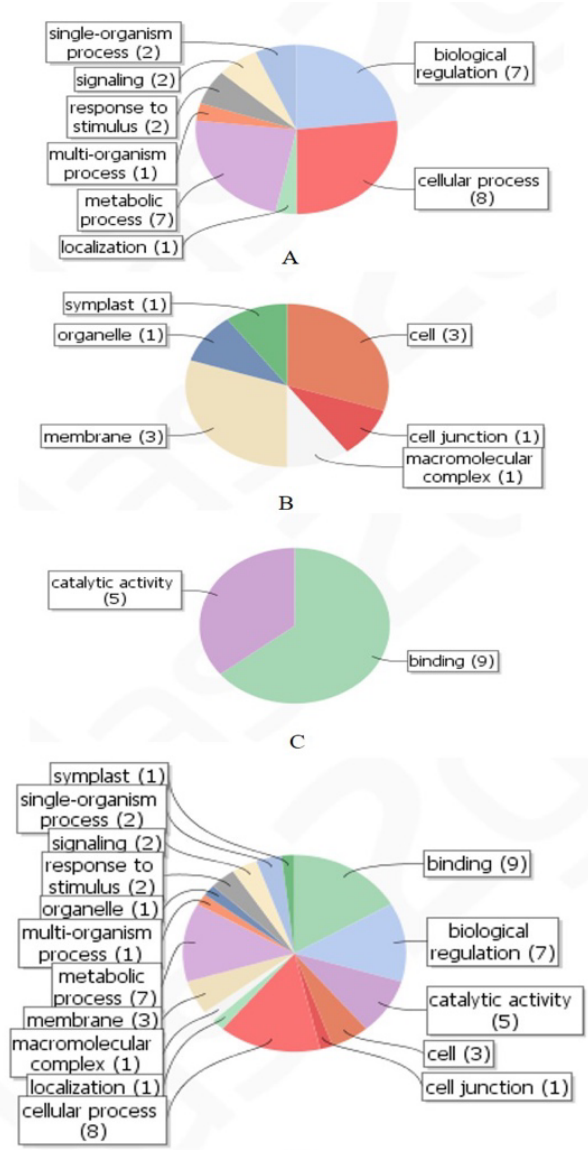

G
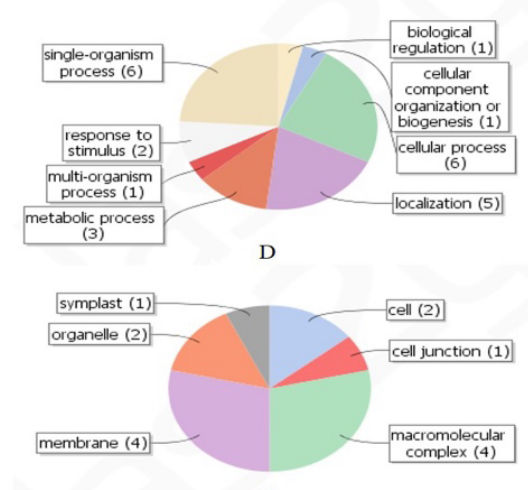

$\mathrm{E}$

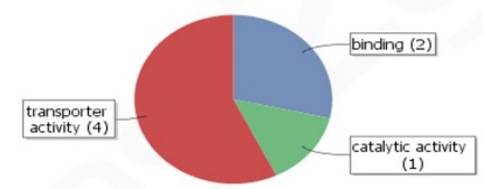

$\mathrm{F}$

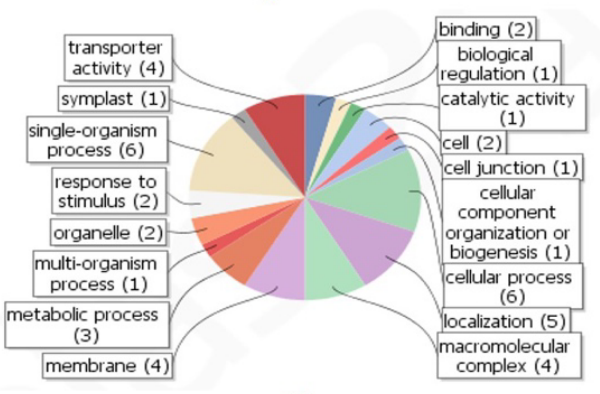

$\mathrm{H}$

Fig. 5. Functional categorization of unisequences in the SSH cDNA libraries. All of the unisequences were clustered into different functional categories after BLASTing against the NCBI database. A, B, C - Biological process, molecular function and cellular component of SMXSP cDNA library; D, E, F -

Biological process, molecular function and cellular component of SMXSB cDNA library; G, H - Combination of all (three) categories of SMXSP and SMXSB cDNA library. 
TABLE III: LOCATION AND FUNCTIONAL ROLE OF DIFFERENTIALLY EXPRESSED SALT RESPONSIVE ESTS IN THE LEAVES OF S. MARITIMA COMPARED WITH THOSE FOUND IN OTHER PLANTS

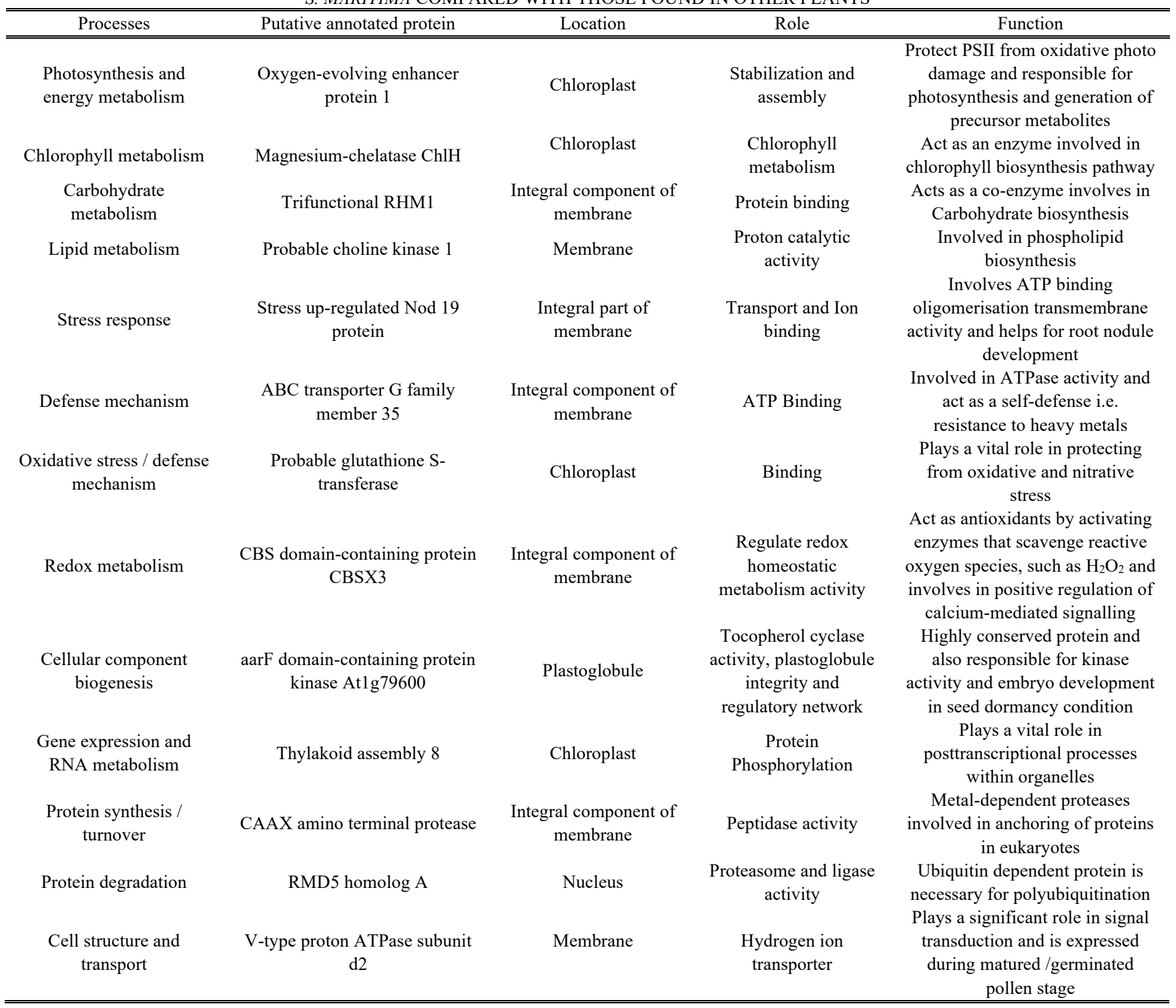

\section{F. Secondary Metabolite Biosynthesis}

Trifunctional UDP RHM1 and Cholone kinase 1 (CK1) were under the category of secondary metabolism. Trifunctional UDP RHM1 is one of the major secondary metabolic enzymes used for flavonol rhamnosylation and mainly involved in UDP-beta-L-rhamnose biosynthesis, a precursor of the primary cell wall components. UDPrhamnose is synthesized from UDP-glucose through the consecutive three-step reaction catalyzed by a single structure enzyme UDP-rhamnose synthase (RHM), which has UDP-Dglucose 4,6- dehydratase, UDP-4-keto-6-deoxy- D-glucose 3,5-epimerase, and UDP-4- keto-rhamnose 4-keto-reductase activities. In A. thaliana, Chenopodium album, Ornithogalum caudatum and Populus euramericana, this enzyme protein defined as a trifunctional plays a significant role in supplying UDP-rhamnose for modification of flavonols ( $\mathrm{Gu}$ et al., 2011; Kim et al., 2013; Han et al., 2015; Yuan et al., 2018) were identified in the present study (clone no.MP 157) might be involved for carbohydrate biosynthesis in S. maritima plants (Fig.5). Another key enzyme is Choline kinase I (CK1), is a primary Cho kinase involved in the phosphatidylcholine subpathway that synthesizes phosphocholine from choline. It encodes kinases with a strict specificity for Cho substrate, suggesting a crucial role of the CDP-Cho pathway in regulating phosphatidylcholine (PC) biosynthesis under abiotic conditions in plants such as salinity, cold and drought. In Arabidopsis and soybean, CK1 were increased under salt treatment which in turn to enhance the synthesis of PC (Begora et al., 2010; Guschina et al., 2014) were upregulated in our study (clone no. MB 51) might be involved in the phospholipid biosynthesis and metabolism in S. maritima (Fig.5).

\section{G. Stress and Defense Mechanism}

Stress upregulated Nod19, Glutathione S-transferases and Cystathionine b-synthase were under the category of stress and defense-related proteins. Nod19 is a serine endopeptidase transcriptional regulator protein encoded by the nod genes are highly responsible for the synthesis and export of specific rhizobial lipochitooligosaccharides were collectively known as Nod factors (NF). It triggers a series of host responses such as root hair deformation, early nodulin gene expression, ion flux changes and transmembrane activity under salinity were reported in Medicago truncatula, pea and other legumes (Doss, 2005; Kelly et al., 2018). This transcript was upregulated in the present study (clone no. MP 28) might be involved stress regulation and transport mechanism in $S$. 
maritima plants (Fig. 5). Glutathione S-transferases (GSTs) is a major class of Phase II detoxification enzymes acts as potential component of catalyzing the conjugation of glutathione (GSH) to electrophilic compounds through thioether linkages. It served as a cellular regulatory role through maintaining intracellular $\mathrm{H}_{2} \mathrm{O}_{2}$ levels, particularly with respect to antioxidant protection of cell membranes. The upregulation of GST upon salt treatment were reported in the differential expression analysis of various halophytes like Aeluropus littoralis, Salicornia brachiata, Suaeda salsa, Suaeda maritima, and Thellungiella hallophila plays a significant role in protecting cells against stress (Wang et al., 2004; Zouari et al., 2007; Sahu \& Shaw, 2009; Tiwari et al., 2016; Li et al., 2020) were identified in our study (clone no. MP 125) might be involved in altering structure and function of proteins from oxidative damage implies its potential role in salt tolerance in $S$. maritima (Fig. 5). In addition, Cystathionine b-synthase (CBS) were also upregulated in the present study (clone no. $M B$ 4) has a characteristic arrangement of three beta sheets and two alpha helices that binds adenosine-containing ligands such as AMP, ATP, or NADPH (Bertoni, 2011). It serves antioxidants by activating thioredoxin enzymes that scavenge reactive oxygen species and involves in positive regulation of calcium-mediated signaling in S. maritima plants (Table III). A similar trend was previously reported in Arabidopsis thaliana annotated as CBSX1 and CBSX2 and in transgenic tobacco over expressing rice by Yoo et al., (2011) and Singh et al., (2012).

\section{H. Cell Organization and Assembly}

Among the identified clones, AARF domain-containing kinase protein were found the maximum number of ESTs clones (clone nos. MP 57, 62, 70, 77, 81) in the present study is found to be characteristic feature of $\mathrm{ABC} 1$ Kinase family (Table 1). Previous studies reported that six isoforms of ABC1-like kinases identified in Arabidopsis under light and salt conditions (Yang et al., 2012) might be involved in plastoglobule morphology, thylakoid integrity or chloroplast regulatory network in $S$. maritima (Fig.5).

\section{RNA Metabolism and Protein Ubiquitination}

Thylakoid assembly 8 (THA8) and RMD5 Homolog A were upregulated in the present study under the category of RNA processing and protein polyubiquitination. Thylakoid assembly 8 is a major subfamily of plant pentatricopeptide repeat (PPR) proteins preceded by a short, conserved Nterminal region and have the potential to mediate specific intermolecular interactions in the processing of mitochondria and chloroplast organelles (Table III). Previous studies shown THA8 should be relatively conserved in maize, rice, and Arabidopsis were highly involved for the splicing of group II introns (Asakura \& Barkan, 2006; Khrouchtchova et al., 2012) which infers TH8 (clone no. MP 58) protein might play a role in RNA editing and processing in S. maritima. Another one is RMD5 Homolog A, an ubiquitin dependent protein plays an important role in E3 ligase activity (Fig.5). It was reported in Arabidopsis and Chenopodium as Gid2/Rmd5, a component of the GID complex plays a key role in regulation and degradation of proteins (Stone et al., 2005; Santt et al., 2008; Gu et al., 2011). In the present study, we have identified 2 clones (clone nos. MP $13 \& 23$ ) shows high homology (98\%) with Chenopodium might play a vital role in polyubiquitination in S. maritima (Table I).

\section{J. Signal Transduction and Vesicular Transport}

Both CAAX proteins and Vacuolar ATPase (V-ATPase) were upregulated in the present study as CAAX proteins (clone no. MP 56) is defined as a group of posttranslational modification proteins encompasses a wide range of molecules such as Ras and a multitude of GTP-binding proteins (G proteins), proteins with $\mathrm{DEAD} / \mathrm{H}$ (Asp-Glu-Ala-Asp/His) box, Ser/Thr protein kinase family, GPRK subfamily, heat shock proteins, etc.(Michaelson et al., 2005) whereas Vacuolar ATPase (V-ATPase) (clone nos. MB 9, 10, 11 \& 31), a highly conserved multisubunit enzyme (Table II) provides the crucial proton motive force necessary for the formation of synaptic vesicles and maintain the balance of vesicular system by interacting with SNAREs and GTPase (Forgac, 2007). Previous studies shown that CAAX in Arabidopsis and V-ATPase in Suaeda salsa plays an important role in cellular signaling processes and regulatory events like transport of molecules, membrane integrity and stability, cell to cell communication and recognition, vesicular trafficking, and indirect regulation of signaling pathways in response to salinity (Bracha et al., 2002; Qiu et al., 2007; Roberts et al., 2008). Hence, both transcripts might play a significant role to protect cell membrane through transport and anchoring of proteins in S. maritima plants (Fig.5).

\section{K. Membrane Transporter}

ATP-binding cassette transporter $G$ 35, which is a subfamily of large, ubiquitous, and diverse group of $\mathrm{ABC}$ transporter super family proteins. It acts as a key player in regulating the physiology and development of plants against biotic and abiotic stress conditions (Hwang et al., 2016). It predominantly assists substrate derivatives of strigolactone plays a significant role for the specificity of secondary metabolite compounds and turns as a potential candidate gene for stress tolerance were reported in Arabidopsis (Liu et al., 2018). This transcript identified in the present study (clone no. MP 29) might be involved in ATPase activity and selfdefense mechanism in $S$. maritima (Fig.5).

\section{CONCLUSION}

In the present study, we provided a comprehensive salt responsive dynamics in the leaves of halophyte Suaeda maritima (L.) Dumort., for long term salt treatment using SSH method. Our results indicated that potential salt responsive candidate genes like Oxygen-evolving enhancer protein 1, AARF domain-containing kinase protein, RMD5 homolog A, V-type proton ATPase subunit d2, ABC transporter $\mathrm{G} 35$ that were mainly involved in photosynthesis, stress and defense response, protein ubiquitination, cellular transport, and secondary metabolites in S. maritima. This will provide a basis study for the mechanism of salt tolerance and may serve as a reference sequence for study of other succulent halophytes. Further analysis of salt responsive genes from this species would unravel novel mechanisms of salt stress tolerance in plants. 


\section{ACKNOWLEDGMENT}

The authors extend their thanks to Professor M.S. Swaminathan for providing facilities and constant support to carry out this research. Thanks to Dr. Sankararamasubramanian, Jenifer and Rani for their cordial support. The funders had no role for writing the manuscript.

\section{FUNDING}

This research was supported by the Department of Biotechnology, Government of India (BT/01/CEIB/09/V/08) for one time grant.

\section{CONFLICT OF INTEREST}

Authors declare that they do not have any conflict of interest.

\section{REFERENCES}

Alhdad, G.M., \& Flowers, T.J. (2020) Salt tolerance in the halophyte Suaeda maritima L. Dum.-the effect of oxygen supply and culture medium on growth. Journal of Soil Science and Plant Nutrition, 21(1), 578-586.

Alhdad, G.M., Seal, C.E., Alazzawi, M.J., Flowers, T.J. The effect of combined salinity and waterlogging on the halophyte Suaeda maritima: The role of antioxidants. Environmental and Experimental Botany, 2013: 87:120-125.

Altschul, S.F., Gish, W., Miller, W., Myers, E.W., Lipman, D.J. Basic local alignment search tool. Journal of Molecular Biology, 5 Oct 1990:215(3):403-410.

Asakura, Y., \& Barkan, A. (2006) Arabidopsis orthologs of maize chloroplast splicing factors promote splicing of orthologous and species specific group II introns. Plant Physiology, 142(4), 1656-1663

Askari, H., Edqvist, J., Hajheidari, M., Kafi, M., Salekdeh, G.H. Effects of salinity levels on proteome of Suaeda aegyptiaca leaves. Proteomics, Apr 2006:6(8):2542 -2554

Begcy, K., Mariano, E.D., Mattiello, L., Nunes, A.V., Mazzafera, P., Maia, I.G., Menossi, M. An Arabidopsis mitochondrial uncoupling protein confers tolerance to drought and salt stress in transgenic tobacco plants. PLoS One, 30 Aug 2011:6(8): e23776

BeGora, M.D., Macleod, M.J.R., McCarry, B.E., Summers, P.S., Weretilnyk, E.A. Identification of phosphomethylethanolamine $N$ methyltransferase from Arabidopsis and its role in choline and phospholipid metabolism. $J$ Biol Chem. 17 Sep 2010:285(38):29147-29155

Bertoni, G. (2011) CBS domain proteins regulate redox homeostasis. Plant Cell, 23, 3562

Bracha, K., Lavy, M., Yalovsky, S. The Arabidopsis AtSTE24 is a CaaX protease with broad substrate specificity. J Biol Chem. 30 May 2002: 277: 29856-29864

Certain, C., Patrona, D.L., Grillon, G.P., Leopold, A., Soudant, P., Grand, L.F. Effect of salinity and nitrogen form in irrigation water on growth, antioxidants and fatty acids profiles in halophytes Salsola australis, Suaeda maritima, and Enchylaena tomentosa for a perspective of biosaline agriculture. Agronomy, 28 Feb 2021:11:449

Cheng, T., Chen, J., Zhang, J., Shi, S., Zhou, Y., Lu, L., et al. Physiological and proteomic analyses of leaves from the halophyte Tangut Nitraria reveals diverse response pathways critical for high salinity tolerance. Front Plant Sci.10 Feb 2015:6:1-13

Diatchenko, L., Lau, Y.F., Campbell, A.P., Chenchik, A., Moqadam, F., Huang, B., et al. Suppression subtractive hybridization: a method for generating differentially regulated or tissue-specific cDNA probes and libraries. Proc Natl Acad Sci U S A.11 Jun 1996:93(12):6025-6030

Doss, R.P. (2005) Treatment of pea pods with Bruchin B results in upregulation of a gene similar to MtN19. Plant Physiol Biochem. 43, 225231.

Flowers, T.J., \& Colmer, T.D. (2015) Plant salt tolerance: adaptations in halophytes. Ann Bot. 115, 327-331.

Forgac, M. (2007) Vacuolar ATPases: rotary proton pumps in physiology and pathophysiology. Nat Rev Mol Cell Biol. 8, 917-929.
Golldack, D., Li, C., Mohan, H., Probst, N. Tolerance to drought and salt stress in plants: unraveling the signaling networks. Front Plant Sci. 22 Apr 2014:5:1-10.

Gu, L., Xu, D., You, T., Li, X., Yao, S., Chen, S., et al. Analysis of gene expression by ESTs from suppression subtractive hybridization library in Chenopodium album L. under salt stress. Mol Biol Rep. Nov 2011:38:5285-5295.

Guschina, I.A., Everard, J.D., Kinney, A.J., Quant, P.A., Harwood, J.L. Studies on the regulation of lipid biosynthesis in plants: application of control analysis to soybean. Biochim Biophys Acta.2014:1838:1488-1500.

Han, X., Qian, L., Zhang, L., Liu, X. Structural and biochemical insights into nucleotide- rhamnose synthase/epimerase-reductase from Arabidopsis thaliana. Biochim Biophys Acta.2015:1854:1476-1486.

Hossain, M.S. (2019) Present scenario of global salt affected soils, its management and importance of salinity research. Int J Biol Science, 1, $1-3$.

Huang, X., \& Madan, A. (1999) CAP3: A DNA sequence assembly program. Genome Research, 9,868-877.

Hwang, J.U., Song, W.Y., Hong, D., Ko, D., Yamaoka, Y., Jang, S., et al. Plant $\mathrm{ABC}$ transporters enable many unique aspects of a terrestrial plant's lifestyle. Mol Plant.7 Mar 2016:9(3):338-355.

Jothiramshekar, S., Benjamin, J.J., Krishnasamy, R., George, S., Swaminathan, R., Parida, A. Identification of salt-responsive genes from $\mathrm{C}_{4}$ halophyte Suaeda nudiflora through suppression subtractive hybridization and expression analysis under individual and combined treatment of salt and elevated carbon dioxide conditions. Physiol Mol Biol Plants. Jan 2020:26(1):163-172.

Kelly, S., Sullivan, J.T., Kawaharada, Y., Radutoiu, S., Ronson, C.W., Stougaard, J. Regulation of Nod factor biosynthesis by alternative NodD proteins at distinct stages of symbiosis provides additional compatibility scrutiny. Environ Microbiol.2018:20: 97-110.

Khrouchtchova, A., Monde, R.A., Barkan, A. A short PPR protein required for the splicing of specific group II introns in angiosperm chloroplasts. $R N A$, Jun 2012:18(6):1197-1209.

Kim, B.G., Jung, W.D., Ahn, J.H. Cloning and characterization of a putative UDP rhamnose synthase 1 from Populus euramericana Guinier, $J$ Plant Biol. 08 Feb 2013:56:7-12.

Koichi, S., Nobutaka, H., Zvy, D., Sigeyuki, B., Isao, K. Molecular characterization of cDNA encoding oxygen evolving enhancer protein 1 increased by salt treatment in the mangrove Bruguiera gymnorrhiza. Plant Cell Physiol. 15 Nov 2000:41(11):1279-1285.

Li H, Wang H, Wen W, Yeng G. The antioxidant system in Suaeda salsa under salt stress. Plant Signal Behav. 2020:15(7):1-6.

Liu, G., Bollier, D., Gübeli, C., Peter, N., Arnold, P., Egli, M., Borghi, L. Simulated microgravity and the antagonistic influence of strigolactone on plant nutrient uptake in low nutrient conditions. NPJ Microgravity, 17 Oct 2018: 4:1-10.

Michaelson, D., Ali, W., Chiu, V.K., Bergo, M., Silletti, J., Wright, L., et al. Postprenylation CAAX processing is required for proper localization of Ras but not Rho GTPases. Mol Biol Cell.2005:16:1606-1616.

Qiu, N., Chen, M., Guo, J., Bao, H., Ma, X., Wang, B. Coordinate upregulation of $\mathrm{V}-\mathrm{H}+-$ ATPase and vacuolar $\mathrm{Na}+/ \mathrm{H}+$ antiporter as a response to $\mathrm{NaCl}$ treatment in a $\mathrm{C} 3$ halophyte Sueda salsa. Plant Sci. 2007:172:1218- 25.

Roberts, P.J., Mitin, N., Keller, P.J., Chenette, E.J., Madigan, J.P., Currin, R.O., et al. Rho Family GTPase modification and dependence on CAAX motif signaled posttranslational modification. $J$ Biol Chem. 12 Sep 2008: 283(37):25150-25163.

Roeurn, S., Hoshino, N., Soejima, K.T., Inoue, Y., Cushman, J.C., Agarie, S. Suppression subtractive hybridization library construction and identification of epidermal bladder cell related genes in the common ice plant, Mesembryanthemumm crystallinum L., Plant Prod Sci. 2016:19:552-561.

Sahu, B.B., \& Shaw, B.P. (2009) Isolation, identification and expression analysis of salt-induced genes in Suaeda maritima, a natural halophyte, using PCR-based suppression subtractive hybridization. BMC Plant Biol. 9, 1-25.

Santt, O., Pfirrmann, T., Braun, B., Juretschke, J., Kimmig, P., Scheel, H., et al. (2008) The yeast GID complex, a novel ubiquitin ligase (E3) involved in the regulation of carbohydrate metabolism. Mol Biol Cell. Aug 2008:19(8):3323-3333.

Shahid, M.A., Sarkhosh, A., Khan, N., Balal, R.M., Ali, S., Rossi, L., et al. Insights into the physiological and biochemical impacts of salt stress on plant growth and development. Agronomy, 30 Jun 2020:10(7):938.

Shrikanth, S.K., George, S., Sankararamasubramanian, H.M., Parida, A. Proteomic analysis of long term salt responsive proteins in the halophyte Suaeda maritima. Plant Omics, 2017:10(4):197-204.

Singh, A.K., Kumar, R., Pareek, A., Sopory, S.K., Pareek, S.L. Over expression of rice CBS domain containing protein improves salinity, 
oxidative, and heavy metal tolerance in transgenic tobacco. $\mathrm{Mol}$ Biotechnol. 4 Feb 2012:52(3):205-216.

Stone, S.L., Hauksdóttir, H., Troy, A., Herschleb, J., Kraft, E., Callis, J. Functional analysis of the RING-type ubiquitin ligase family of Arabidopsis. Plant Physiol. Jan 2005:137(1):13-30.

Tiwari, V., Patel, M.K., Chaturvedi, A.K., Mishra, A., Jha, B. Functional characterization of the tau class glutathione-S-transferases gene (SbGSTU) promoter of Salicornia brachiata under salinity and osmotic stress. PLoS One, 17 Feb 2016:11: e0148494.

Wang, Z.I., Li, P.H., Fredricksen, M., Gong, Z.Z., Kim, C.S., Zhang, C., et al. Expressed sequence tags from Thellungiella halophila, a new model to study plant salt- tolerance. Plant Sci.2004:166:609-616.

Wong, Y.Y., Ho, C.L., Nguyen, P.D., Teo, S.S., Harikrishnan, J.A., Rahim, R.A., et al. Isolation of salinity tolerant genes from the mangrove plant, Bruguiera cylindrica by using suppression subtractive hybridization (SSH) and bacterial functional screening. Aquat Bot.2007:86:117-122.

Yang, S., Zeng, X., Li, T., Liu, M., Zhang, S., Gao, S., et al. AtACDO1, an $\mathrm{ABC} 1$-like kinase gene, is involved in chlorophyll degradation and the response to photooxidative stress in Arabidopsis. J Exp Bot. Jun 2012:63(12):3959-3973.

Yoo, K.S., Ok, S.H., Jeong, B.C., Jung, K.W., Cui, M.H., Hyoung, S., et al. Single cystathionine $\mathrm{b}$-synthase domain-containing proteins modulate development by regulating the thioredoxin system in Arabidopsis. Plant Cell, Oct 2011:23(10):3577-3594.

Yuan, F., Guo, J., Shabala, S., Wang, B. Reproductive physiology of halophytes: current standing. Front Plant Sci.2019:9:1954.

Yuan, S., Yin, S., Liu, M., Kong, J.Q. Isolation and characterization of a multifunctional flavonoid glycosyltransferase from Ornithogalum caudatum with glycosidase activity. Sci Rep.12 Apr 2018:8:1-13.

Zhang, J.L., Bai, R., Flowers, T.J., Wang, C.M., Wetson, A.M., Duan, H.R., Wang, S.M. (2020) Dynamic responses of the halophyte Suaeda maritima to various levels of external $\mathrm{NaCl}$ concentration. In Grigore M.N, (Eds.), Handbook of Halophytes (pp 1-22). Springer, Cham.

Zouari, N., Ben, S.R., Legavre, T., Azaza, J., Sabau, X., Jaoua, M., et al. Identification and sequencing of ESTs from the halophyte grass Aeluropus littoralis. Gene, 09 Sep 2007:404(1-2):61-69.

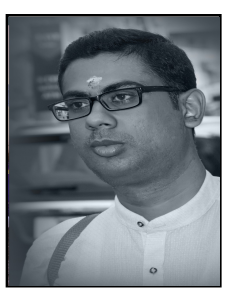

K Shrikanth was born on 21/07/1989 at Madurai, India. He has completed his Post graduation in Microbiology at Bharathidasan University, India.

$\mathrm{He}$ is presently doing Doctoral Research Scholar at Department of Molecular Biology and Biotechnology, M.S. Swaminathan Research Foundation and Government Arts College, Nandanam under University of Madras, India. He is having a vast research experience in the field of Microbiology and OMICS technologies using various Bioinformatics tools. His major work in identifying stress tolerant genes and proteins specifically for salt in the halophytic plants (Mangroves).

Mr. Shrikanth is renowned as Subject / Industry expert in the Meeting of Board of Studies for Post-graduation and Master of Philosophy programme in Microbiology under Madurai Kamaraj University, Madurai. He is a Member in IIMAR regarding to promote the prudent use of antibiotics as to reduce possibility of spread of antibiotic resistance. He is a Member in ADNAT, CCMB to promote DNA Fingerprinting and other DNA Technologies and their applications. He is one of the Member in National Green Crops/Eco Club for maintaining a sustainable, clean and green environment sponsored by Department of Environment

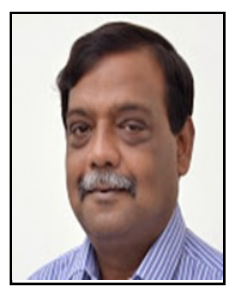

A. K. Parida* was born on 12/12/1963 and completed his Doctor of Philosophy at Delhi University.

$\mathrm{He}$ is presently Director, Institute of Life Sciences, Bhubaneswar, India. He has made notable research contributions in the field of agriculture, plant molecular biology and biotechnology. His pioneering contributions in identifying stress tolerant genes specifically for salt and drought stress. His research has contributed to the basic understanding of the genetic architecture and species relationship in mangroves, cereals, legumes and other cultivated crop species. He has supervised 25 students for their Ph.D. degree, published more than 100 peer reviewed publications and travelled to more than 30 countries.

Dr. Ajay Parida is Elected Fellow of the National Academy of Agriculture Sciences (NAAS) and National Academy of Sciences of India (NASI). He is a recipient of several awards and recognition including Padma Shri in 2014 for his outstanding contribution in the field of Science and Engineering. Prior to this, he has served as Executive Director of M. S. Swaminathan Research Foundation, Chennai.

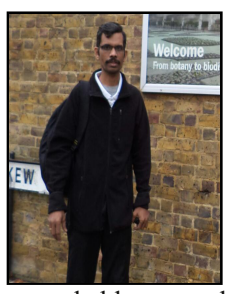

K. P. Girivasan* was born on $25 / 07 / 1970$. He has completed his Doctor of Philosophy at University of Madras.

$\mathrm{He}$ is presently Associate Professor and Head, Department of Botany, Government Arts College for Men (Autonomous), Nandanam, Chennai. He is expertise in the field of isolating, identifying fungi from different substrates, screening for enzymes and fungal hormones and statistical analysis. He has made remarkable research contributions in the field of plant taxonomy, mycology, plant pathology and biotechnology. He is having more than 25 years of research and teaching experience and has published many peer reviewed papers.

Dr. Girivasan is an academic visitor of the School of Life Sciences, Nottingham University, United Kingdom for the abroad study programme. $\mathrm{He}$ is a member of Syllabus framing for Biology and Botany Higher Secondary Education, Govt. of Tamil Nadu. He is also a Member for Board of Studies (Subject Expert) for Aided and Government Colleges of University of Madras and Puducherry. He is the Coordinator of Tree Census in Tamil Nadu Forest Department (Urban Forestry Division), Tamilnadu, India. 